\title{
Discovery of osmotic sensitive transcription factors in fish intestine via a transcriptomic approach
}

\author{
Marty Kwok-Shing Wong ${ }^{1 *}$, Haruka Ozaki ${ }^{2}$, Yutaka Suzuki ${ }^{2}$, Wataru Iwasaki ${ }^{1,2,3}$ and Yoshio Takei ${ }^{1}$
}

\begin{abstract}
Background: Teleost intestine is crucial for seawater acclimation by sensing osmolality of imbibed seawater and regulating drinking and water/ion absorption. Regulatory genes for transforming intestinal function have not been identified. A transcriptomic approach was used to search for such genes in the intestine of euryhaline medaka.

Results: Quantitative RNA-seq by Illumina Hi-Seq Sequencing method was performed to analyze intestinal gene expression 0 h, 1 h, 3 h, 1 d, and $7 \mathrm{~d}$ after seawater transfer. Gene ontology (GO) enrichment results showed that cell adhesion, signal transduction, and protein phosphorylation gene categories were augmented soon after transfer, indicating a rapid reorganization of cellular components and functions. Among $>50$ transiently up-regulated transcription factors selected via co-expression correlation and GO selection, five transcription factors, including CEBPB and CEBPD, were confirmed by quantitative PCR to be specific to hyperosmotic stress, while others were also up-regulated after freshwater control transfer, including some well-known osmotic-stress transcription factors such as SGK1 and TSC22D3/ Ostf1. Protein interaction networks suggest a high degree of overlapping among the signaling of transcription factors that respond to osmotic and general stresses, which sheds light on the interpretation of their roles during hyperosmotic stress and emergency.
\end{abstract}

Conclusions: Since cortisol is an important hormone for seawater acclimation as well as for general stress in teleosts, emergency and osmotic challenges could have been evolved in parallel and resulted in the overlapped signaling networks. Our results revealed important interactions among transcription factors and offer a multifactorial perspective of genes involved in seawater acclimation.

Keywords: Transcriptome, Fish osmoregulation, Intestine, Seawater acclimation, Transcription factors, CEBPB, CEBPD, SGK1, TSC22D3

\section{Background}

Osmoregulation is an important topic in fish physiology. Bony fishes maintain their body fluid osmolality approximately one-third that of seawater (SW) and therefore they constantly lose water and gain ions in SW but gain water and lose ions in fresh water (FW). Osmoregulation consumes a high proportion of daily energy expenditure in teleosts as they either actively excrete excess ions in SW or take up ions in FW against the respective concentration gradients [1]. The gills, kidney, and intestine are major osmoregulatory organs and play different roles

\footnotetext{
* Correspondence: martywong@aori.u-tokyo.ac.jp

'Atmosphere and Ocean Research Institute, The University of Tokyo, Tokyo, Japan

Full list of author information is available at the end of the article
}

to maintain body fluid homeostasis in both FW and SW $[2,3]$. SW teleosts drink copiously and the gastrointestinal tract is responsible for water absorption to compensate for the water loss by osmosis [4,5]. Although the intestine is an internal organ, its lumen directly contacts environmental water upon drinking in teleost fishes. Osmosensing in fish is accomplished by a combination of sensors in the central nervous system and peripheral osmoregulatory epithelia such as gill, nasal cavity, and intestine [6]. A reflex inhibition in drinking was demonstrated in eel intestine in response to $\mathrm{Cl}^{-}$ions (but not $\mathrm{Na}^{+}$) in ingested fluid, indicating the presence of a $\mathrm{Cl}^{-}$specific sensor in eel intestine [7].

Euryhaline fishes that are able to acclimate in both FW and SW transform their intestines dramatically to fulfill the appropriate osmoregulatory roles. When the 
eel is transferred from FW to SW, the intestinal wall decreases in thickness, and the anterior intestine became highly vascularized through angiogenesis within 1-2 days [8]. Monovalent ions $\left(\mathrm{Na}^{+}, \mathrm{Cl}^{-}\right)$in the imbibed SW are actively absorbed while divalent ions $\left(\mathrm{Ca}^{2+}, \mathrm{Mg}^{2+}, \mathrm{SO}^{2-}\right)$ are precipitated to decrease luminal fluid osmolality [5,9]. The composition of epithelial transporters is also reorganized extensively. An upregulation of mucosal $\mathrm{Na}-\mathrm{K}-2 \mathrm{Cl}$ cotranspoter (NKCC2/ SLC12A1) remarkably increases the ion absorption rate, which is facilitated by the serosal Na-KATPase and $\mathrm{Na}^{+}$-bicarbonate exchanger [10]. The rapid and efficient ion absorption mechanism in teleost intestine is unique in vertebrates [11]. The SW teleost intestine is an absorptive epithelium that is similar to the thick ascending loop of Henle in mammalian nephron, and thus was often used as a comparative model for the study of kidney tubules, especially in the study of transporter mechanisms and cellular regulation in response to volume and salt stresses [12]. Several hormones such as cortisol, prolactin, growth hormone, atrial natriuretic peptide, arginine vasotocin, guanylin, and vasoactive intestinal peptide regulate transepithelial ion transport [13-20]. However, the transcription factors that govern hormone actions, cell proliferation, apoptosis, angiogenesis, transporter metabolism etc., are unclear.

Transcriptomic approaches have been used to investigate the dynamics osmoregulatory organ function of teleosts [21-24]. However, microarray- or pyrosequencing-based transcriptomic reads do not provide sufficient depth and coverage for the detection and quantitation of low expression genes, which may result in a biased discovery towards high expression genes. In the present study, the objective was to discover the transcription factors that are responsive to the SW challenge in medaka intestine. Illumina HiSeq Sequencing was selected to provide a deep coverage of identified genes as the large number of reads allows quantification of gene expression by mapping to reference genome, and is usually sufficient to detect most expressed gene even at low expression level [25], which is an ideal choice at a cost-performance perspective. Medaka was used owing to the relative completeness of the genome data, which can streamline the RNA-seq analysis and guarantee high accuracy and reliability. Medaka is also a euryhaline species that can survive a direct FW to $50 \% \mathrm{SW}$ (ca. twice hypertonic to plasma) transfer [26]. We combined physiological and bioinformatic approaches in the experimental design, in which FW medaka was challenged by $50 \%$ SW transfer and time-dependent changes in intestinal transcriptome were analyzed by RNA-seq. We focused on the early upregulated transcription factors that could initiate subsequent intestinal transformations and lead to altered function from FW to SW.

\section{Results}

Illumina sequencing and reference gene mapping

Illumina $101 \mathrm{bp}$ paired end sequencing were performed on all 25 intestine samples collected from medaka after $0 \mathrm{~h}, 1 \mathrm{~h}, 3 \mathrm{~h}, 1 \mathrm{~d}$, and $7 \mathrm{~d}$ after SW transfer $(\mathrm{N}=5)$ The sequenced reads ranged from 17.3 to 60.5 million reads with average 37.9 million reads in each sample (Table 1). The read were mapped against the annotated genome of Medaka. More than $83 \%$ of the sequences were successfully mapped sequences, indicating the data sets are representative.

\section{Gene ontology analysis}

GO terms enriched in the $1 \mathrm{~h}$-after-SW transfer group are listed in Table 2. According to biological process, protein phosphorylation, regulation of DNA-dependent transcription, cell adhesion, and signal transduction were highly ranked in GO enrichment. According to molecular function, protein binding, protein tyrosine kinase activity, protein serine/threonine kinase activity, and actin binding were enriched. According to cellular component, significant enrichment in GO terms was found in integrin complex and cytoskeleton.

\section{Transiently upregulated genes}

The intestinal transcription-related genes that are involved in the SW acclimation were screened from the genes with early transient increase in expression, which is defined as genes with significant increases in gene expression (one-way ANOVA, Tukey; $p<0.05$ ) in $1 \mathrm{~h}$ and/or $3 \mathrm{~h}$ post-transfer groups compared to those of $0 \mathrm{~h}$, $1 \mathrm{~d}$, and $7 \mathrm{~d}$. The candidates genes were further filtered to remove low expression genes ( $<20 \mathrm{RPM}$ at $1 \mathrm{~h}$ or $3 \mathrm{~h}$ posttransfer). Genes with significant correlation (Pearson $r>0.8$ ) in expression with a known osmotic transcription factor (TSC22D3) among the early transient increase genes were selected for further analysis (Additional file 1: Table S1). The selected genes were further filtered by $\mathrm{GO}$ annotation to obtain transcription-related genes and 57 genes were further analyzed by real-time PCR.

\section{Real-time PCR}

To confirm the adequacy of the SW transfer stimulus on the medaka intestine, SLC12A1/NKCC2 and AQP1 were used as reference genes since these transporters are well-acknowledged to change in teleost intestine after SW challenges [27-29]. The real-time PCR results of SLC12A1 and AQP1 showed a gradual increase and decrease in gene expression at $1 \mathrm{~d}$ and $7 \mathrm{~d}$ post-transfer respectively, which strongly mirrored the RNA-seq results 
Table 1 Illumina sequencing and mapping statistics

\begin{tabular}{|c|c|c|c|c|c|c|c|c|c|}
\hline Sample & Treatment & $\begin{array}{l}\text { Number } \\
\text { of reads }\end{array}$ & $\begin{array}{l}\text { Number of } \\
\text { mapped }\end{array}$ & $\begin{array}{l}\text { Number of } \\
\text { unique read }\end{array}$ & $\begin{array}{l}\text { Number of } \\
\text { multiple }\end{array}$ & $\begin{array}{l}\text { Number of } \\
\text { unmapped }\end{array}$ & $\begin{array}{l}\% \\
\text { mapped }\end{array}$ & $\begin{array}{l}\% \\
\text { unique }\end{array}$ & $\begin{array}{l}\% \text { concordantly mapped } \\
\text { pair/mapped pair }\end{array}$ \\
\hline medaka_DT1 & FW & $45,187,196$ & $38,886,015$ & $36,800,226$ & $2,085,798$ & $6,301,181$ & 86.06 & 81.44 & 96.04 \\
\hline medaka_DT2 & FW & $60,510,650$ & $51,531,207$ & $48,089,685$ & $3,441,522$ & $8,979,443$ & 85.16 & 79.47 & 96.32 \\
\hline medaka_DT3 & FW & $49,132,444$ & $42,149,176$ & $39,787,090$ & $2,362,086$ & $6,983,268$ & 85.79 & 80.98 & 96.01 \\
\hline medaka_DT4 & FW & $53,098,918$ & $45,320,354$ & $42,439,720$ & $2,880,634$ & $7,778,564$ & 85.35 & 79.93 & 96.12 \\
\hline medaka_DT5 & FW & $42,600,708$ & $36,530,248$ & $34,556,499$ & $1,973,749$ & $6,070,460$ & 85.75 & 81.12 & 96.46 \\
\hline medaka_DT6 & SW1h & $42,628,084$ & $36,663,691$ & $34,708,187$ & $1,955,504$ & $5,964,393$ & 86.01 & 81.42 & 95.96 \\
\hline medaka_DT7 & SW1h & $56,932,366$ & $48,827,425$ & $46,194,052$ & $2,633,373$ & $8,104,941$ & 85.76 & 81.14 & 96.90 \\
\hline medaka_DT8 & SW1h & $42,093,406$ & $36,151,083$ & $34,098,610$ & $2,052,473$ & $5,942,323$ & 85.88 & 81.01 & 96.47 \\
\hline medaka_DT9 & SW1h & $52,158,762$ & $44,893,371$ & $42,420,952$ & $2,472,419$ & $7,265,391$ & 86.07 & 81.33 & 96.05 \\
\hline medaka_DT10 & SW1h & $36,707,006$ & $31,548,390$ & $29,929,884$ & $1,618,506$ & $5,158,616$ & 85.95 & 81.54 & 96.06 \\
\hline medaka_DT11 & SW3h & $41,952,606$ & $36,052,499$ & $34,168,827$ & $1,883,672$ & $5,900,107$ & 85.94 & 81.45 & 95.05 \\
\hline medaka_DT12 & SW3h & $38,901,344$ & $33,331,036$ & $31,561,823$ & $1,769,213$ & $5,570,308$ & 85.68 & 81.13 & 96.60 \\
\hline medaka_DT13 & SW3h & $48,830,644$ & $42,173,994$ & $39,875,418$ & $2,298,576$ & $6,656,650$ & 86.37 & 81.66 & 94.54 \\
\hline medaka_DT14 & SW3h & $43,038,240$ & $37,145,021$ & $35,132,181$ & $2,053,293$ & $6,445,624$ & 85.80 & 81.28 & 96.36 \\
\hline medaka_DT15 & SW3h & $45,401,548$ & $38,955,924$ & $36,902,631$ & $2,053,293$ & $6,445,624$ & 85.80 & 81.28 & 96.36 \\
\hline medaka_DT16 & SW1d & $41,811,642$ & $35,924,612$ & $34,060,638$ & $1,863,974$ & $5,887,030$ & 85.92 & 81.46 & 96.24 \\
\hline medaka_DT17 & SW1d & $27,329,496$ & $23,684,730$ & $22,440,772$ & $1,243,958$ & $3,644,766$ & 86.66 & 82.11 & 95.70 \\
\hline medaka_DT18 & SW1d & $26,278,316$ & $22,719,337$ & $21,476,111$ & $1,243,226$ & $3,558,979$ & 86.46 & 81.73 & 95.82 \\
\hline medaka_DT19 & SW1d & $20,440,212$ & $20,139,877$ & $19,080,869$ & $1,059,008$ & $3,300,335$ & 85.64 & 81.09 & 96.01 \\
\hline medaka_DT20 & SW7d & 23,440212 & $20,139,877$ & $19,080,869$ & $1,059,008$ & $3,300,335$ & 85.92 & 81.40 & 96.56 \\
\hline medaka_DT21 & sW7d & $20,399,688$ & $17,475,541$ & $16,546,834$ & 928,707 & $2,924,147$ & 85.67 & 81.11 & 96.54 \\
\hline medaka_DT22 & SW7h & $17,289,434$ & $14,563,145$ & $13,793,496$ & 769,649 & $2,726,289$ & 84.23 & 79.78 & 96.92 \\
\hline medaka_DT23 & SW7h & $\begin{array}{l}23,527 \\
904\end{array}$ & $19,851,220$ & $18,617,357$ & $1,233,863$ & $3,676,684$ & 84.37 & 79.13 & 97.13 \\
\hline medaka_DT24 & SW7h & $27,563,352$ & $23,083,585$ & $21,713,537$ & $1,370,048$ & $4,479,767$ & 83.75 & 78.78 & 97.48 \\
\hline medaka_DT25 & SW7h & $21,133,038$ & $18,209,017$ & $17,192,056$ & $1,016,961$ & $2,924,021$ & 86.16 & 81.35 & 96.18 \\
\hline
\end{tabular}

DT: digestive tract; FW: freshwater; SW: 50\% seawater.

(Figure 1). FW control transfer did not induce significant changes in gene expressions.

The same set of cDNA was subsequently used for validation of transcription factors and 19/57 of the transiently upregulated genes were reproducible (Figure 2). Among the genes in which transient upregulation was confirmed by quantitative PCR, 14/19 were found to be stress-related since similar increases were observed after FW-FW transfer, including TSC22D3 and SGK1 (Figure 2; Additional file 2: Figure S1-S4). However, 5 novel transcription factors, CEBPB, CEBPD, RAD54L2, HIF3A, and LDB1, were discovered to respond specifically to SW challenges, and thus used for further analyses.

\section{STRING analysis and protein interaction network assembly}

Using the STRING analysis, protein interaction networks of hyperosmotic-related (Figure 3) and stress-related (Figure 4) transcription factors were constructed by overlapping the common interacting protein partners. Stress-related transcription factors such as SGK1, TSC22D3, NR0B2, and DDIT4 interact with the UBC-, TP53-, and RELA-related networks (Figure 4). Hyperosmotic-specific transcription factors such as CEBPB and CEBPD affect a similar protein network including UBC and RELA (Figure 3). EP300, CREBBP, and ATXN1 were only found in salinityspecific network, and these could have specific roles on transforming the intestine from FW- to SW-types.

\section{Discussion}

\section{GO enrichment}

As the focus of the present study is on the early transcription factors that may signal the transformation of intestinal functions, GO comparison was performed between pre-transfer $(\mathrm{FW})$ and $1 \mathrm{~h} \mathrm{SW}$ transfer groups. The results indicated that the intestine transcriptome responded rapidly to the change in environment salinity and the GO terms enriched were highly relevant to the 
Table 2 Gene ontology enrichment analysis on the transcriptomes of FW vs SW 1 h in medaka intestine ( $p<0.05)$

\begin{tabular}{|c|c|c|c|c|c|c|}
\hline \multirow[b]{2}{*}{ Rank } & \multirow{2}{*}{$\begin{array}{l}\text { Biological process } \\
\text { Annotation }\end{array}$} & \multirow[b]{2}{*}{ p-value } & \multicolumn{2}{|l|}{ Molecular function } & \multicolumn{2}{|l|}{ Cellular component } \\
\hline & & & Annotation & p-value & Annotation & p-value \\
\hline 1 & protein phosphorylation & $1.90 \mathrm{E}-10$ & protein binding & $8.60 \mathrm{E}-13$ & integrin complex & $1.60 \mathrm{E}-03$ \\
\hline 2 & regulation of transcription, DNA-dependent & $1.10 \mathrm{E}-08$ & protein tyrosine kinase activity & $8.10 \mathrm{E}-08$ & extra cellular region & 7.50E-03 \\
\hline 3 & cell adhesion & 4.20E-05 & protein serine/threonine kinase activity & $1.70 \mathrm{E}-05$ & Cytoskeleton & 8.60E-03 \\
\hline 4 & $\begin{array}{l}\text { regulation of small GTPase mediated signal } \\
\text { transduction }\end{array}$ & $2.20 \mathrm{E}-04$ & actin binding & 4.20E-05 & $\begin{array}{l}\text { proteinaceous } \\
\text { extracellur matri }\end{array}$ & 2.30E-02 \\
\hline 5 & signal transduction & 2.20E-04 & $\begin{array}{l}\text { sequence-specific DNA binding } \\
\text { transcripttion factor activity }\end{array}$ & 5.30E-05 & & \\
\hline 6 & integrin-mediated signaling pathway & $1.01 \mathrm{E}-03$ & $\begin{array}{l}\text { guanyl-nucleotide exchange factor } \\
\text { activity }\end{array}$ & 5.70E-04 & & \\
\hline 7 & intracellular signal transduction & $1.72 \mathrm{E}-03$ & phospholipid binding & $1.35 \mathrm{E}-03$ & & \\
\hline 8 & glucose metabolic process & $1.94 \mathrm{E}-03$ & sequence-specific DNA binding & $2.12 \mathrm{E}-03$ & & \\
\hline 9 & cytokine-mediated signaling pathway & $2.27 \mathrm{E}-03$ & $\begin{array}{l}\text { non-membrane spanning protein } \\
\text { tyrosine kinase activity }\end{array}$ & $2.69 \mathrm{E}-03$ & & \\
\hline 10 & peptidy I-tyrosine dephosphorylation & $2.43 \mathrm{E}-03$ & cytokine receptor activity & $2.69 \mathrm{E}-03$ & & \\
\hline 11 & cell cycle arrest & 4.30E-03 & ATP binding & $3.86 \mathrm{E}-03$ & & \\
\hline 12 & multicellular organismal development & $5.18 \mathrm{E}-03$ & $\begin{array}{l}\text { G-protein coupled peptide receptor } \\
\text { activity }\end{array}$ & $3.90 \mathrm{E}-03$ & & \\
\hline 13 & $\begin{array}{l}\text { G-protein coupled receptor signaling } \\
\text { pathway }\end{array}$ & 5.90E-03 & protein domain specific binding & 4.53E-03 & & \\
\hline 14 & neurotransmitter transport & $9.35 \mathrm{E}-03$ & MAP kinase activity & 5.07E-03 & & \\
\hline 15 & intracellular protein kinase cascade & $1.75 \mathrm{E}-02$ & $\begin{array}{l}\text { protien tyrosine/serine/threonine } \\
\text { phosphatase activity }\end{array}$ & $5.98 \mathrm{E}-03$ & & \\
\hline 16 & MAPK cascade & $1.79 \mathrm{E}-02$ & receptor activity & $6.97 \mathrm{E}-03$ & & \\
\hline 17 & $\begin{array}{l}\text { transmembrane receptor protein tyrosine } \\
\text { kinase signaling pat... }\end{array}$ & 1.93E-02 & calcium ion binding & 7.11E-03 & & \\
\hline 18 & positive regulation of GTPase activity & $2.71 \mathrm{E}-02$ & protein tyrosine phosphatase activity & $1.02 \mathrm{E}-02$ & & \\
\hline 19 & regulation of cellular component biogenesis & 2.71E-02 & $\begin{array}{l}\text { transmembrane receptor protein tyrosine } \\
\text { kinase activity }\end{array}$ & $1.62 \mathrm{E}-02$ & & \\
\hline 20 & hormophilic cell adhesion & $\begin{array}{l}3.446 \mathrm{E}- \\
02\end{array}$ & GTPase activator activity & $1.76 \mathrm{E}-02$ & & \\
\hline 21 & regulation of ARF protein signal transduction & $3.48 \mathrm{E}-10$ & $\begin{array}{l}\text { neurotransmitter: sodium symporter } \\
\text { activity }\end{array}$ & $2.08 \mathrm{E}-02$ & & \\
\hline 22 & $\begin{array}{l}\text { regulation of cellular component } \\
\text { organization }\end{array}$ & $3.48 \mathrm{E}-02$ & small GTPase regulator activity & $2.20 \mathrm{E}-02$ & & \\
\hline 23 & cell-matrix adhesion & 4.77E-02 & calmodulin binding & $2.65 \mathrm{E}-03$ & & \\
\hline 24 & polyol metabolic process & $4.88 \mathrm{E}-02$ & $\begin{array}{l}\text { organic acid transmembrane transporter } \\
\text { activity }\end{array}$ & $2.89 \mathrm{E}-02$ & & \\
\hline 25 & & & ubiquitin protein ligase activity & 2.99E-02 & & \\
\hline 26 & & & protein complex binding & $3.27 \mathrm{E}-02$ & & \\
\hline 27 & & & $\begin{array}{l}\text { phosphotransferase activity, alcohol } \\
\text { group as acceptor }\end{array}$ & $3.67 \mathrm{E}-02$ & & \\
\hline 28 & & & $\begin{array}{l}\text { ARF guanyl-nucleotide exchange factor } \\
\text { activity }\end{array}$ & $3.92 \mathrm{E}-02$ & & \\
\hline 29 & & & signal transducer activity & 4.66E-02 & & \\
\hline 30 & & & kinase activity & 4.79E-02 & & \\
\hline
\end{tabular}

contemporary understanding of the transformation events occurred in fish intestine when entering SW [5]. GO annotations including signal transduction, regulation of transcription, protein phosphorylation, regulation of gene expression were all markedly enriched, indicating neuronor hormone-mediated signals were commanding the 
A RNA-seq (SLC12A1)

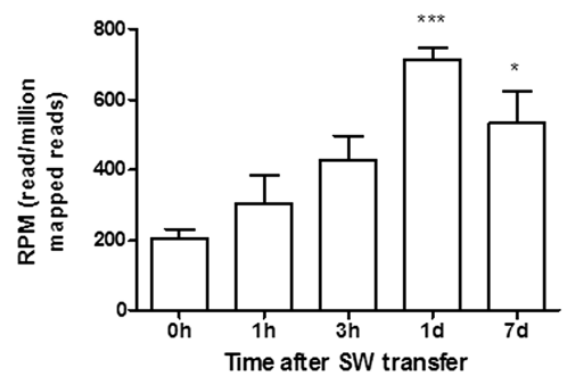

C RNA-seq (AQP1)

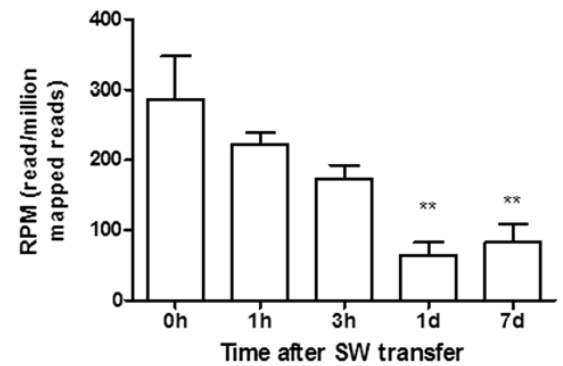

B Realtime PCR (SLC12A1)

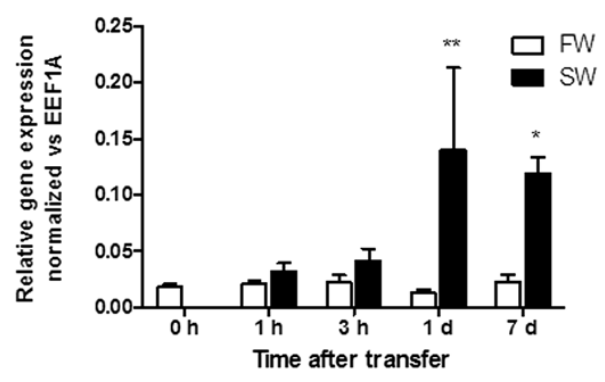

D Realtime PCR (AQP1)

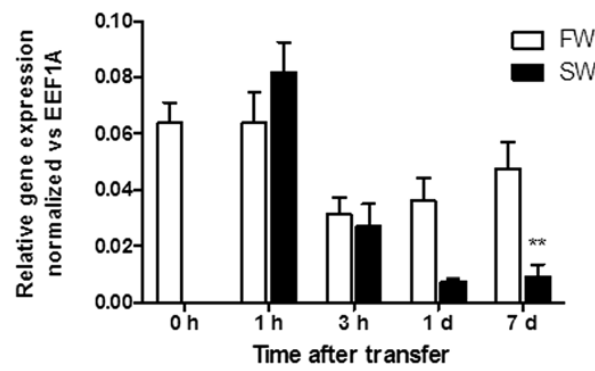

Figure 1 Representative validation of quantitative transcriptome by realtime PCR. RNA-seq and realtime PCR results of time course expression profiles of SLC12A1 (A and B) and AQP1 (C and D) are shown respectively. Statistical significant groups are indicated by asterisks (one-way ANOVA, Tukey for $\mathbf{A}$ and $\mathbf{C}$; two-way ANOVA, Bonferroni for $\mathbf{B}$ and $\mathbf{D}$ with time-matched comparison. $\left.{ }^{*} p<0.05 ;{ }^{* *} p<0.01 ;{ }^{* * *} p<0.001\right)$.

structural and functional changes. For cellular function, actin binding, and cell adhesion enhancement may indicate that the cells adaptively respond to the cellular dehydration by adjusting the membrane permeability and cytoplasmic osmolytes to increase survival. Markers of cell cycle arrest were enriched and suggested an increase in apoptosis and recruitment of new cells to proliferate in SW. Glucose metabolic process and ATP-binding enrichment indicated a high energy turnover following adrenergic response to cope with the abrupt transfer stress, and to provide energy for cell homeostasis. Augmentation in peptide receptor and kinase activities indicated a role of endocrine stimulation in the transformation including the various changes in ion transporter expressions. The enrichment in integrin complex and cytoskeleton also indicates stress responses at both membrane and cytoplasm levels, which could be related to cellular dehydration consequent to imbibition of SW. Altogether, these changes are expected during transformation of intestinal functions from FW- to SW-types, which include apoptosis of old cells and recruitment of new cells, reorganization of transporters for ion/water absorption, and changes in paracellular permeability.

\section{Validation of seawater treatment effects}

In order to validate the accuracy and reproducibility of current transcriptome analyses, genes that are known to change consistently after SW transfer were compared between transcriptome and real-time PCR data. The NKCC2 expression increased while AQP1 expression decreased similarly in both analyses (Figure 1), indicating high reliability of the current analyses. The results confirmed the reproducibility of the SW transfer effects and thus allow the extrapolation of the data sets for the discovery of novel genes related to SW acclimation. The increased NKCC2 gene expression was consistent with the increased ion absorption in SW teleost intestine $[27,28]$. However, the decreased AQP1 expression in medaka intestine after SW transfer was puzzling since SW acclimation up-regulated AQP1 expression in the eel intestine but down-regulated that in seabream [30-32]. The down-regulation of AQP1 in medaka intestine could be similar to that of seabream, but the physiological implication of this species-specific difference is not clear because a high demand for water absorption by the intestine of SW teleost is expected. A search for expression pattern of other AQP members in the transcriptome data was performed but all known AQPs in medaka did not increase their expression levels in SW (data not shown), thus ruling out the possibility that some other AQP members may have replaced the function of $\mathrm{AQP1}$ in medaka intestine. The species-specific difference in AQP1 expression may also indicate that the various intestinal ion transporting mechanisms could be present in different teleost lineages. 


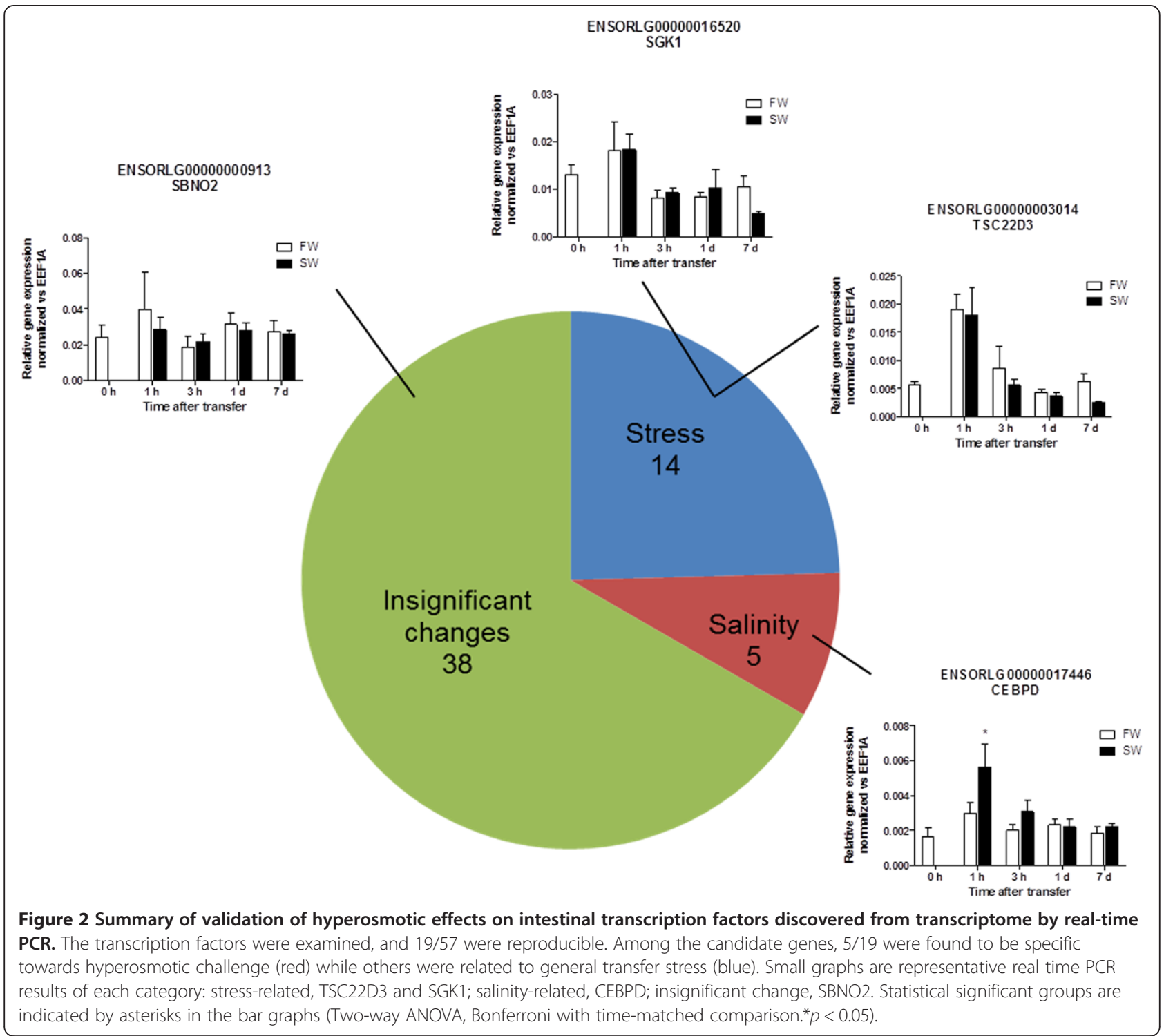

\section{Novel transcription factors for osmoregulation}

CEBPB and CEBPD are important transcriptional activators in the immune and inflammatory responses via cytokines such as interleukin 6 [33]. High salt intake increased the transcription of angiotensinogen by decreasing the methylation around the CEBP binding sites at the promoter region [33], thus CEBP may contribute to the control of the renin-angiotensin system at the transcriptional level. Multiple CEBP binding sites are present on the promoter region of NKCC2 in mice [34]. CEBP binding sites in the promoter region control the gene expression of cystic fibrosis transmembrane conductance regulator (CFTR) in human under basal and cAMP-stimulated transcription states [35]. In addition, the protein interaction network identified in this study indicates possible involvement of a cAMP-related pathway, represented by CREBBP, in the initial signaling in SW intestine transformation. Therefore,
CEBP binding sites at the promoter regions of ion transporters will be of high interest in the future studies.

RAD54L2 is a DNA helicase that modulates androgen receptor-dependent transactivation in a promoterdependent manner. The osmoregulatory function of this helicase is unknown and it is possibly one of the glucocorticoid receptor regulatory elements in fish, which facilitate or mediate the mineralocorticoid actions of cortisol. HIF3A is known to be involved in the adaptive response to hypoxia and interacts with a number of stress-related proteins including HSP90. The SW challenge may have increased energy consumption for reorganization of cellular components, which led to cellular hypoxia. LDB1 was recently regarded as a master gene for the control of red blood cell development [36]. The possible role of LDB1 could be as a regulator of KLF1, which in turn modulates the expressions of water channel AQP1 and cell adhesion 


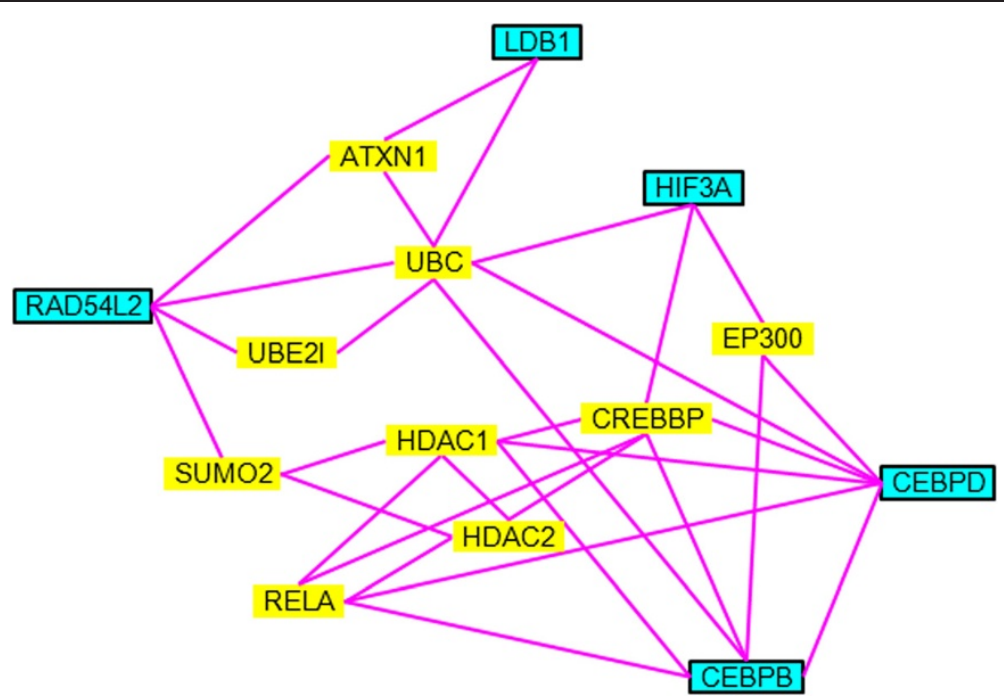

Figure 3 Protein interaction network of salinity-related transcription factors. Genes highlighted in blue represent the salinity-related transcription factors discovered from transcriptome studies. Yellow highlighted genes indicate the protein interaction partners extracted from STRING analysis.

molecule CD44 [37]. Therefore, LDB1 could regulate expression of transporters and act as an upstream controller for cell adhesion and cytoskeleton as indicated in the GO analysis.

Besides the 5 salinity-specific transcription factors discovered in this study, ATXN1, EP300, and CREBBP, which are independent of the stress-related interacting proteins, were also singled out from the protein interaction networks (Figures 3 and 4). The functional role of ATXN1 in mammals is not clear but our results suggest that ATXN1 directly interacts with salinity-specific transcription factors
LDB1 and RAD54L2, which could be a novel regulatory factor under salt stress. CREBBP is an important mediator in the cAMP signaling. In fact, the cAMP pathway was shown to be involved in the osmoregulatory sensing and functions in teleosts [38-41]. EP300 is a tumor-related transcription factor that is involved in restraining cell growth and division. EP300 also mediates cAMP-gene regulation by specific binding to phosphorylated CREBBP and acts as a co-activator of HIF1A in mammals [42]. It is possible that the EP300 in fish may interact with HIF3A as suggested by out protein interaction network.

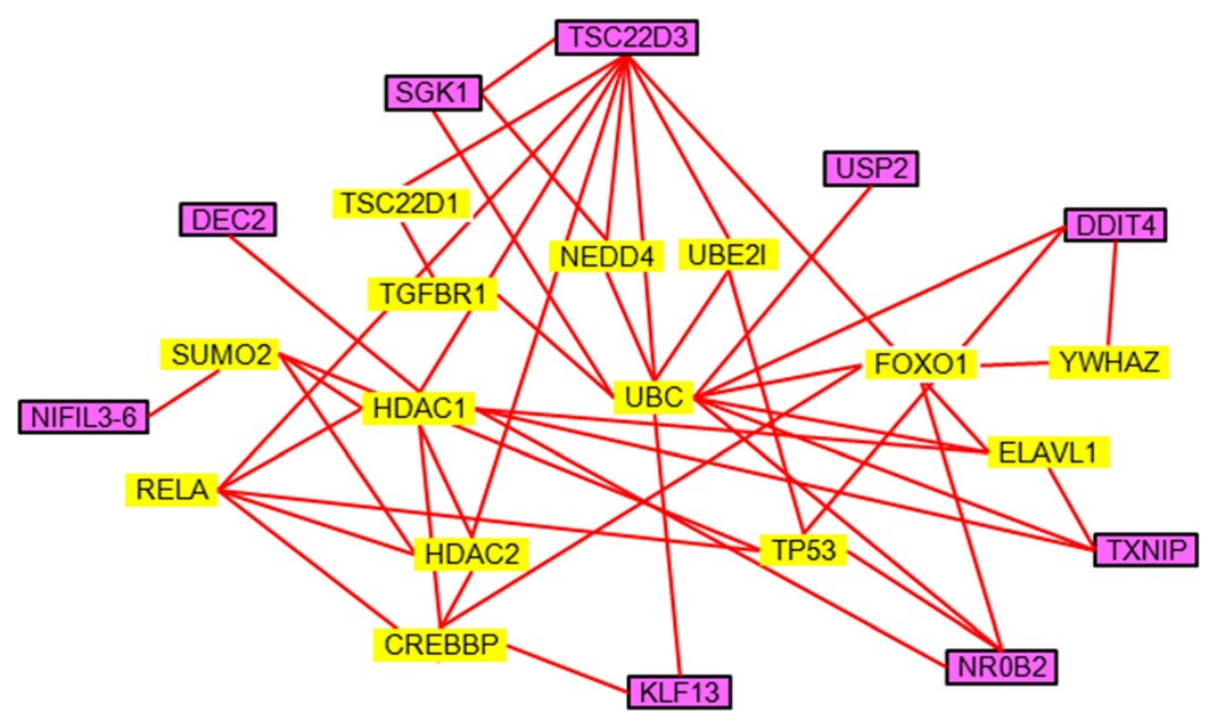

Figure 4 Protein interaction network of stress-related transcription factors. Genes highlighted in purple represent the stress-related transcription factors discovered from transcriptome studies. Yellow highlighted genes indicate the protein interaction partners extracted from STRING analysis. 


\section{Stress-related transcription factors}

Previous studies have demonstrated that TSC22D3 and serum/glucocorticoid regulated kinase (SGK1) are osmotic stress regulators in the gill of several fish models including killifish, medaka, eel, and tilapia [43-49]. In medaka intestine, however, we found that their upregulation soon after SW transfer is partly due to handling stress as shown by the real time PCR results in FW control transfer (Figure 2). The discrepancy could be due to the difference in tissues (gill vs. intestine) but we noticed that previous studies were lacking proper time-dependent control transfer, and where the salinity effects were concluded by the comparison between pre-transfer and post-transfer groups [24]. Another possibility is that some of these stress-related transcription factors are also involved in the regulation of ion transport, amelioration of cellular stress such as DNA damage, and mobilization of energy via adrenergic stimulation. In fish opercular epithelium, $\alpha$ - and $\beta$-adrenergic stimulation can inhibit and stimulate ion transport via $\mathrm{Ca}^{2+} / \mathrm{IP}_{3}$ and cAMP signaling pathways respectively [50].

The overlapping of stress- and salinity-related transcription factor interaction networks infers an intimate relationship between general emergency responses and osmoregulation (Figures 3 and 4). In fact, the effects of handling stress on the perturbation of hydromineral balance and osmoregulatory functions in fish were documented [43,51]. During an emergency, as induced by handling, fish inevitably increase their ventilation rate to obtain sufficient oxygen to meet the energy demand. However, the increase in ventilation also elevates ion and water fluxes, disrupting the equilibrium of ion absorption/excretion [51]. Activity or expression of Na-K-ATPase and Na$\mathrm{K}-2 \mathrm{Cl}$ co-transporter changed in accordance to the changes of plasma osmolality induced by handling stress [43]. Stress undoubtedly increases metabolic demand, and it was argued that the metabolic performance of fish is limited by osmoregulatory cost [52]. In the light of these findings, some of the stress-related transcription factors could also be related to the perturbation of hydromineral balance.

Previous studies demonstrated a role of SGK1 in salinity acclimation via controlling the activities of ion transporters in fish $[45,53]$. SGK1 expression is ubiquitous and upregulated by a large number of stimuli including hyperosmotic or isotonic cell shrinkage, excessive glucose concentration, mechanical stress, metabolic acidosis, oxidative stress, heat shock, and DNA damage [54]. Leptin was shown to promote glucose mobilization during SW transfer in tilapia [55], indicating a hormonedriven hyperglycemia under a hyperosmotic challenge. Therefore, it is possible that emergency responses, such as an increase in plasma glucose, may lead to an artefactual increase in SGK1 expression. SGK1 is a powerful modulator for gene expression and phosphorylation of a large number of ion transporters such as Na-K-ATPase,
NKCC2, and CFTR [56]. In addition, SGK1 is highly expressed in tumor cells and it phosphorylates EP300 to acetylate NF-kB [57] and is downregulated by ubiquitination via NEDD4-2 [58]. Our protein interaction network (Figure 4) also suggested a wide spread interactions of SGK1 with other transcription factors, in particular with TSC22D3. TSC22D3 was firstly suggested to be acting as a osmotic-stress transcription factor 1 (Ostf1) [1] as the expression was upregulated by hyperosmotic challenge and the protein is localized in ionocytes of the teleost gills $[44,59]$. However, recent studies suggested a wide spectrum of TSC22D3 functions in developmental regulation, reproduction, inflammation, and tumor suppression $[60,61]$, and it may play a major role as a glucocorticoidinduced leucine zipper. Both SGK1 and TSC22D3 are mediators of glucocorticoids and thus their roles in osmoregulation could be related to the release of cortisol, which acts as the mineralocorticoid as well as the glucocorticoid in teleosts [62]. Therefore, their functions may not be directly specific to osmotic stimulus but rather related to the pathway dependent stimulation.

Other stress-related genes such as DDIT4 and TXNIP are negative regulators to cellular stress and were stimulated by glucose increment [63]. NR0B2, also known as small heterodimer partner, is an orphan nuclear receptor that represses transcription and interacts with EP300 [64]. KLF13 is also a transcription repressor that binds to basic-transcription element [65]. From the individual gene function to the interaction network, these stress-related transcription factors play vital roles in cell survival and emergency preparation, which is important under both general and osmotic stresses.

\section{Conclusion}

Our work for the first time investigated quantitatively the transcriptome of fish intestine in response to SW transfer in a time-course manner. This bottom-up approach has allowed the discovery of novel transcription factors involved in the osmoregulatory response to SW challenge. Results of GO analysis showed that the transcriptome analysis revealed representative changes and the data sets are valuable for discovering novel genes involved in salinity acclimation in fish. The protein interaction networks of the salinity- and stress-related genes indicate overlapping of the transcription factors between emergency and SW acclimation (see Figure 5 for summary). The newly-discovered salinity-related transcription factors provide important directions on the studies in osmoregulation and its regulation in fishes.

\section{Methods}

Animal husbandry

Medaka (Oryzias lapties), HdrR strain, were bred and kept in a freshwater (FW) recirculating aquarium system in the Atmosphere and Ocean Research Institute, The 


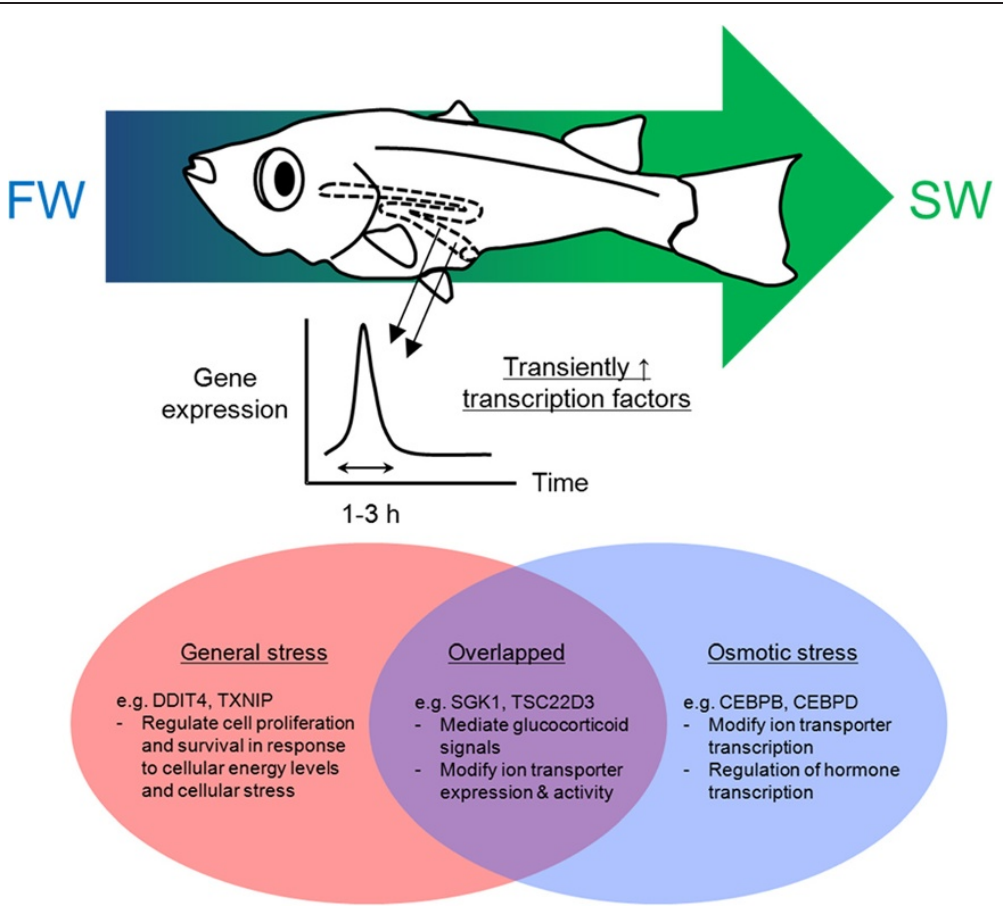

Figure $\mathbf{5}$ Graphical summary of the key findings. The early transiently-upregulated transcription factors can be categorized into two groups: general stress vs osmotic stress. Among these transcription factors, some are common to the two groups and could be important in glucocorticoid-mediating functions.

University of Tokyo. The aquarium system was controlled at $26^{\circ} \mathrm{C}$ with a photoperiod of $14 \mathrm{~h} / 10 \mathrm{~h}$ light/dark cycle. Fish were fed daily with freshly hatched brine shrimp. Individuals (1.0 - $1.2 \mathrm{~g}$ body weight) were randomly divided into nine experimental tanks ( $\mathrm{N}=6$ in each group). Four groups were transferred to FW (control-transfer) and another four groups were transferred to $50 \%$ seawater (SW) for $1 \mathrm{~h}, 3 \mathrm{~h}, 1 \mathrm{~d}$, and $7 \mathrm{~d}$, respectively. One group remained undisturbed to serve as a pre-transfer control. In sampling, the experimental fish was anaesthetized in $0.1 \%$ tricaine methanesulfonate (MS-222) and then sacrificed by spinal transection. The intestine was immediately dissected, snap-frozen in liquid nitrogen, and stored at $-80^{\circ} \mathrm{C}$ until use. Experiments were repeated twice to obtain sufficient RNA samples for transcriptome and realtime PCR analyses. All animal experiments were carried out according to the ethical guidelines and protocols approved by the Animal Experiment Committee of the University of Tokyo.

\section{RNA sequencing}

Total RNA was extracted from the intestine samples using Isogen (Nippon Gene, Toyama) according to the manufacturer's protocols. RNA quality was monitored using an Agilent 2100 Bioanalyzer system (Agilent Technology, CA ) and only RNA samples with RNA integrity number values over 7.0 were used for sequencing. The
cDNA libraries were prepared from the RNA samples of 5 treatment groups (FW, SW 1 h, 3 h, 1 d, and $7 \mathrm{~d} ; \mathrm{N}=5$ in each case) using TruSeq RNA Sample Preparation v2 (Illumina Inc., CA), and were sequenced by Illumina HiSeq 2500 (101 bp, paired-end) in the Laboratory of Functional Genomics, The University of Tokyo, according to the manufacturer's protocols. From the Illumina chastity filter analysis, the percentages of reads that passed the filter (PF reads), the percentage of bases with $>=$ Q30 in the PF reads, and the mean quality score of the PF reads were of $96.06 \pm 0.59,93.78 \pm 0.83$, and $36.23 \pm 0.26$, respectively. We performed the FastQC analysis on the PF reads, uniquely mapped reads, and unmapped reads. The percentage of reads with mean sequence quality $>=$ Q30 was $94.32 \pm 1.21,96.76 \pm 1.02$, and $83.52 \pm 1.58$, respectively, indicating that the quality of the unmapped reads was lower than that of the uniquely mapped reads (Additional file 3: Table S2).

\section{Reference genome sequence and annotation data}

The medaka HdrR genome sequence was obtained from UCSC Genome Browser [oryLat2, http://genome.ucsc.edu/]. The annotated gene models (NCBIM37) and the annotation of rRNAs were taken from Ensembl [release 69, http://www. ensembl.org/]. The annotations of tRNAs were retrieved from UCSC Genome Browser [http://genome.ucsc.edu/]. 


\section{RNA-seq data analysis}

The RNA-seq data were mapped to the medaka genome using TopHat (version 2.0.9) with default parameters [66]. Sequence reads that were mapped to multiple genes or positions were removed. HTSeq (version 0.5.3p9) were used to count the number of reads mapped on each gene [67]. For normalization, the count for each gene was divided by the number of million uniquely mapped reads in each sample (RPM; read per million mapped reads). Genes that did not have more than five normalized counts in at least two samples were removed from further analyses.

\section{Gene ontology (GO) analysis}

The GO terms of all transcripts in SW $1 \mathrm{~h}$ group were compared with those of FW group using topGO package (version 2.14.0) in Bioconductor [http://www.bioconductor.org/] with the weight01 algorithm to calculate an enrichment score for each gene ontology term [68]. Significantly-enriched GO terms were ranked using the $p$-values with threshold at $p<0.05$.

\section{Gene expression profile analysis}

To extract the transcription-related genes that are involved in the SW acclimation in the intestine, genes with early transient increase in expression were screened. Early transient increase is defined as significant increase in gene expression (one-way ANOVA, Tukey; $p<0.05$ ) in $1 \mathrm{~h}$ and/or $3 \mathrm{~h}$ post-transfer groups compared to those of $0 \mathrm{~h}, 1 \mathrm{~d}$, and $7 \mathrm{~d}$. As the number of genes that fell in this category was too large for further analysis, we further narrowed the candidates by filtering genes with $<20$ RPM at $1 \mathrm{~h}$ or $3 \mathrm{~h}$ post-transfer. The expression profile of a representative gene (TSC22D3) in the early transient increase category was used to search for co-expressed genes in the transcriptome using Pearson's correlation and genes that exhibited $r>0.8$ among the 25 samples were selected for further analysis. Gene description and GO annotation of these genes were obtained at Uniprot Knowledge Database. Genes with "transcription" and/or "DNA-binding" in the description or GO terms were screened and further analyzed by real-time PCR.

\section{Real-time PCR}

To validate the hyperosmotic effects that were discovered in transcriptome analysis, we performed real-time PCR on the selected genes using a separate set of RNA samples from a duplicate experiment as described in the previous section. We included control transfer (FW to FW) samples to check whether the observed effects are salinity-specific or are due to simply the physical transfer $(\mathrm{N}=6$ at each time point). Total RNA was extracted and subsequently treated with DNase I (Life Technologies, CA) to remove genomic DNA and $1 \mu \mathrm{g}$ of the treated RNA was reversetranscribed with Iscript cDNA Synthesis Kit (Bio-Rad, CA) according to the manufacturer's protocols. Real-time PCR was performed in $10 \mu \mathrm{L}$ reactions using Kappa SYBR 2X PCR mix (Kappa Biosystems, MA) and ABI 7900HT Fast Real Time PCR System (Life Technologies, CA). The amplification of a single amplicon was confirmed by analyzing the melting curve after the real-time cycling. Elongation factor 1 alpha (EEF1A) was used as an internal control to normalize the gene expressions among different samples. Our transcriptome data also indicated a stable expression of EEF1A among all samples (data not shown), as expected for an internal control housekeeping gene. Ion transporters such as $\mathrm{Na}-\mathrm{K}-\mathrm{Cl}$ co-transporter (SLC12A1) and aquaporin (AQP1) were included as positive controls for SW transfer effects on the intestine. Relative expression of target genes was quantified by the 2-[delta][delta]Ct method where [delta][delta] $\mathrm{Ct}=[$ delta $]$ Ct,target $-[$ delta $] \mathrm{Ct}, \mathrm{EEF} 1 \mathrm{~A}$. Real time PCR primer sequences are listed in Additional file 4: Table S3.

Gene expressions in intestine at various times following FW-FW and FW-SW transfers were analyzed by two-way ANOVA followed by Bonferroni's multiple-comparison test. Time-matched group comparison was made and groups with $p<0.05$ were considered as significantly different (GraphPad Prism Ver. 5.0 for Windows, CA). Genes with increased expression in respond to SW transfer but not FW transfer $1 \mathrm{~h}$ and/or $3 \mathrm{~h}$ while insignificant changes at other time points were considered as salinity-specific. Genes with increase expression in respond to both FW and $\mathrm{SW}$ transfer at $1 \mathrm{~h}$ and/or $3 \mathrm{~h}$ while insignificant changes at other time points were considered as stress-related.

\section{Protein-protein interaction by STRING analysis}

After validation of transiently upregulated genes by realtime PCR, the selected transcription factors were further divided into 3 categories (see real-time PCR results). The transcription factors specific to handling stress or SW challenge were searched for potential interacting proteins using the Known and Predicted Protein-Protein Interaction Database (STRING 9.05). The interacting proteins were extracted from the database using human as the model organism since the database coverage is higher than those of medaka or zebrafish. Protein interaction networks were constructed by connecting the overlapped genes among the query genes and interacting proteins.

\section{Data availability}

The sequencing data sets for the RNA-seq are available from the DDBJ/EBI/NCBI databases with accession number DRP002295.

\section{Additional files}

Additional file 1: Table S1. Early transient upregulated genes after a time-course SW transfer ( $1 \mathrm{~h}$ and/or $3 \mathrm{~h}$ vs $0 \mathrm{~h}, 1 \mathrm{~d}$, and 7d; one-way ANOVA, Tukey; $p<0.05$ ). 
Additional file 2: Figures S1-S4. Real time PCR results of the transcription factors in medaka intestine discovered from transcriptome. The expression patterns were categorized to salinity-related, stress-related, and insignificant changes. Statistical significant groups are indicated by asterisks in the bar graphs (two-way ANOVA, Bonferroni with time-matched comparison. ${ }^{*} p<0.05$ )

Additional file 3: Table S2. Quality controls using Casava and FastQC. $\% \geq$ Q30: the percentages of reads whose mean sequence quality were $\geq$ Q30. DT: digestive tract; FW: freshwater; SW: 50\% seawater.

Additional file 4: Table S3. Primer sequences for real time PCR.

\section{Abbreviation}

AQP1: Aquaporin 1; ATXN1: Ataxin 1; CAMP: cyclic-AMP; CD44: CD44 Molecule; CEBP: CCAAT/Enhancer Binding Protein (C/EBP); CEBPB: CCAAT/ Enhancer Binding Protein (C/EBP), Beta; CEBPD: CCAAT/Enhancer Binding Protein (C/EBP), Delta; CFTR: Cystic Fibrosis Transmembrane Conductance Regulator; CREBBP: CREB Binding Protein; DDIT4: DNA-Damage-Inducible Transcript 4; EEF1A: Eukaryotic Translation Elongation Factor 1 Alpha 1; EP300: E1A Binding Protein P300; GO: Gene Ontology; HIF1A: Hypoxia Inducible Factor 1, Alpha Subunit; HIF3A: Hypoxia Inducible Factor 3, Alpha Subunit; HSP90: Heat Shock Protein 90; IP ${ }_{3}$ : Inositol trisphosphate; KLF1: Kruppel-Like Factor 1 (Erythroid); KLF13: Kruppel-Like Factor 13; LDB1: LIM Domain Binding 1; MS-222: Tricaine methanesulfonate; NKCC2/ SLC12A1: Na-K-2Cl Cotransporter; Solute Carrier Family 12: Member 1; NROB2: Nuclear Receptor Subfamily 0, Group B, Member 2; RAD54L2: Androgen Receptor-Interacting Protein 4; RELA: V-Rel Avian Reticuloendotheliosis Viral Oncogene Homolog A1; RNA-seq: RNA sequencing; SGK1: Serum/Glucocorticoid Regulated Kinase 1; TP53: Tumor Protein P53; TSC22D3: TSC22 Domain Family, Member 3; TXNIP: Thioredoxin Interacting Protein; UBC: Ubiquitin C.

\section{Competing interests}

The authors declare that they have no competing interests.

\section{Authors' contributions}

MW wrote the manuscript, maintained fish stock, performed RNA extraction, STRING analysis, real time PCR, and data analyses. $\mathrm{HO}$ and WI analyzed sequencing data, performed mapping, and analyzed GO enrichment. YS performed the RNA sequencing. YT supervised the project, designed and coordinated the experiment. All authors read, edited, and approved the final manuscript.

\section{Acknowledgement}

This work is supported by Grant-in-Aid for Scientific Research on Innovation Areas "Genome Science" (221S0002) from Ministry of Education, Culture, Sports, Science and Technology of Japan to YT, and Grant-in-Aid for Scientific Research (23247010) and (23710231) from Japan Society for the Promotion of Science to YT and WI respectively. We appreciate the technical assistance provided by Kiyomi Imamura, Terumi Horiuchi and Makiko Tosaka of the Laboratory of Functional Genomics, the University of Tokyo. The super computer resource was provided by National Institute of Genetics (NIG), Research Organization of Information and Systems (ROIS). MW, HO, and IW were supported by Centers of Research Excellence in Science and Technology (CREST).

\section{Author details}

${ }^{1}$ Atmosphere and Ocean Research Institute, The University of Tokyo, Tokyo, Japan. ${ }^{2}$ Department of Computational Biology, Graduate School of Frontier Sciences, The University of Tokyo, Tokyo, Japan. ${ }^{3}$ Department of Biological Sciences, Graduate School of Science, The University of Tokyo, Tokyo, Japan.

Received: 2 May 2014 Accepted: 9 December 2014

Published: 18 December 2014

\section{References}

1. Kidder GW 3rd, Petersen CW, Preston RL: Energetics of osmoregulation: II. Water flux and osmoregulatory work in the euryhaline fish, Fundulus heteroclitus. J Exp Zool A Comp Exp Biol 2006, 305(4):318-327.

2. Beyenbach KW: Kidneys sans glomeruli. Am J Physiol Renal Physiol 2004, 286(5):F811-F827.
3. Hwang PP, Lee TH, Lin LY: Ion regulation in fish gills: recent progress in the cellular and molecular mechanisms. Am J Physiol Regul Integr Comp Physiol 2011, 301(1):R28-R47.

4. Nobata S, Ando M, Takei Y: Hormonal control of drinking behavior in teleost fishes; insights from studies using eels. Gen Comp Endocrinol 2013, 192:214-221.

5. Whittamore JM: Osmoregulation and epithelial water transport: lessons from the intestine of marine teleost fish. J Comp Physiol B 2012, 182(1):1-39.

6. Kültz D: The combinatorial nature of osmosensing in fishes. Physiology (Bethesda) 2012, 27(4):259-275.

7. Ando $\mathrm{M}$, Nagashima $\mathrm{K}$ : Intestinal $\mathrm{Na}^{+}$and $\mathrm{Cl}^{-}$levels control drinking behavior in the seawater-adapted eel Anguilla japonica. J Exp Biol 1996, 199(Pt 3):711-716.

8. Takei $Y$, Yuge $S$ : The intestinal guanylin system and seawater adaptation in eels. Gen Comp Endocrinol 2007, 152(2-3):339-351.

9. Mekuchi M, Watanabe S, Kaneko T: Bicarbonate secreted from the pancreas contributed to the formation of Ca precipitates in Japanese eel, Anguilla japonica. J Exp Zool A Ecol Genet Physiol 2013, 319(1):53-62

10. Taylor JR, Mager EM, Grosell M: Basolateral NBCe1 plays a rate-limiting role in transepithelial intestinal $\mathrm{HCO}^{-}$secretion, contributing to marine fish osmoregulation. J Exp Biol 2010, 213(3):459-468

11. Scott GR, Baker DW, Schulte PM, Wood CM: Physiological and molecular mechanisms of osmoregulatory plasticity in killifish after seawater transfer. J Exp Biol 2008, 211(Pt 15):2450-2459.

12. Lionetto $\mathrm{MG}$, Schettino $\mathrm{T}$ : The $\mathrm{Na}^{+}-\mathrm{K}^{+}-2 \mathrm{Cl}^{-}$cotransporter and the osmotic stress response in a model salt transport epithelium. Acta Physiol (OXf) 2006, 187(1-2):115-124.

13. Ando $\mathrm{M}$, Kondo $\mathrm{K}$, Takei $\mathrm{Y}$ : Effects of eel atrial natriuretic peptide on $\mathrm{NaCl}$ and water transport across the intestine of the seawater eel. J Comp Physiol B 1992, 162(5):436-439.

14. Bakker R, Dekker K, De Jonge HR, Groot JA: VIP, serotonin, and epinephrine modulate the ion selectivity of tight junctions of goldfish intestine. Am J Physiol 1993, 264(2 Pt 2):R362-R368.

15. Ferlazzo A, Carvalho ES, Gregorio SF, Power DM, Canario AV, Trischitta F, Fuentes J: Prolactin regulates luminal bicarbonate secretion in the intestine of the sea bream (Sparus aurata L.). J Exp Biol 2012, 215(Pt 21):3836-3844.

16. Kalujnaia S, Wilson GD, Feilen AL, Cramb G: Guanylin-like peptides, guanylate cyclase and osmoregulation in the European eel (Anguilla anguilla). Gen Comp Endocrinol 2009, 161(1):103-114.

17. Martos-Sitcha JA, Gregório SF, Carvalho ES, Canario AV, Power DM, Mancera $J M$, Martínez-Rodríguez G, Fuentes J: AVT is involved in the regulation of ion transport in the intestine of the sea bream (Sparus aurata). Gen Comp Endocrinol 2013, 193:221-228.

18. O'Grady SM, Wolters PJ: Evidence for chloride secretion in the intestine of the winter flounder. Am J Physiol 1990, 258(2 Pt 1):C243-C247.

19. Tsukada T, Takei Y: Integrative approach to osmoregulatory action of atrial natriuretic peptide in seawater eels. Gen Comp Endocrinol 2006, 147(1):31-38.

20. Yuge $S$, Takei Y: Regulation of ion transport in eel intestine by the homologous guanylin family of peptides. Zoolog Sci 2007, 24(12):1222-1230.

21. Fiol DF, Kültz D: Rapid hyperosmotic coinduction of two tilapia (Oreochromis mossambicus) transcription factors in gill cells. Proc Natl Acad Sci U S A 2005, 102(3):927-932.

22. Kalujnaia S, McWilliam IS, Zaguinaiko VA, Feilen AL, Nicholson J, Hazon N, Cutler CP, Cramb G: Transcriptomic approach to the study of osmoregulation in the European eel Anguilla anguilla. Physiol Genomics 2007, 31(3):385-401.

23. Tse WK, Sun J, Zhang H, Law AY, Yeung BH, Chow SC, Qiu JW, Wong CK: Transcriptomic and iTRAQ proteomic approaches reveal novel short-term hyperosmotic stress responsive proteins in the gill of the Japanese eel (Anguilla japonica). J Proteomics 2013, 89:81-94.

24. Whitehead A, Roach JL, Zhang S, Galvez F: Salinity- and populationdependent genome regulatory response during osmotic acclimation in the killifish (Fundulus heteroclitus) gill. J Exp Biol 2012, 215(Pt 8):1293-1305

25. Liu Y, Ferguson JF, Xue C, Silverman IM, Gregory B, Reilly MP, Li M: Evaluating the impact of sequencing depth on transcriptome profiling in human adipose. PLoS One 2013, 8(6):e66883.

26. Inoue $K$, Takei Y: Diverse adaptability in oryzias species to high environmental salinity. Zoolog Sci 2002, 19(7):727-734.

27. Cutler CP, Cramb G: Differential expression of absorptive cation-chloridecotransporters in the intestinal and renal tissues of the European eel 
(Anguilla anguilla). Comp Biochem Physiol B Biochem Mol Biol 2008, 149(1):63-73.

28. Gregório SF, Carvalho ES, Encarnação S, Wilson JM, Power DM, Canário AV, Fuentes J: Adaptation to different salinities exposes functional specialization in the intestine of the sea bream (Sparus aurata L.). J Exp Biol 2013, 216(Pt 3):470-479.

29. Watanabe $S$, Mekuchi M, Ideuchi $H$, Kim YK, Kaneko T: Electroneutral cation- $\mathrm{Cl}^{-}$cotransporters $\mathrm{NKCC} 2 \beta$ and $\mathrm{NCC} \beta$ expressed in the intestinal tract of Japanese eel Anguilla japonica. Comp Biochem Physiol A Mol Integr Physiol 2011, 159(4):427-435.

30. An KW, Kim NN, Choi CY: Cloning and expression of aquaporin 1 and arginine vasotocin receptor mRNA from the black porgy, Acanthopagrus schlegeli: effect of freshwater acclimation. Fish Physiol Biochem 2008, 34(2):185-194.

31. Aoki M, Kaneko T, Katoh F, Hasegawa S, Tsutsui N, Aida K: Intestinal water absorption through aquaporin 1 expressed in the apical membrane of mucosal epithelial cells in seawater-adapted Japanese eel. J Exp Biol 2003, 206(Pt 19):3495-3505.

32. Martinez AS, Cutler CP, Wilson GD, Phillips C, Hazon N, Cramb G: Regulation of expression of two aquaporin homologs in the intestine of the European eel: effects of seawater acclimation and cortisol treatment. Am J Physiol Regul Integr Comp Physiol 2005, 288(6):R1733-R1743.

33. Wang F, Demura M, Cheng Y, Zhu A, Karashima S, Yoneda T, Demura Y, Maeda $Y$, Namiki M, Ono K, Nakamura $Y$, Sasano H, Akagi T, Yamagishi M Saijoh K, Takeda Y: Dynamic CCAAT/enhancer binding protein-associated changes of DNA methylation in the angiotensinogen gene. Hypertension 2014, 63(2):281-288.

34. Igarashi P, Whyte DA, Li K, Nagami GT: Cloning and kidney cell-specific activity of the promoter of the murine renal Na-K-C1 cotransporter gene. J Biol Chem 1996, 271(16):9666-9674.

35. Pittman N, Shue G, LeLeiko NS, Walsh MJ: Transcription of cystic fibrosis transmembrane conductance regulator requires a CCAAT-like element for both basal and CAMP-mediated regulation. J Biol Chem 1995, 270(48):28848-28857.

36. Love PE, Warzecha C, Li L: Ldb1 complexes: the new master regulators of erythroid gene transcription. Trends Genet 2014, 30(1):1-9.

37. Arnaud L, Saison C, Helias V, Lucien N, Steschenko D, Giarratana MC, Prehu C, Foliguet B, Montout L, de Brevern AG, Francina A, Ripoche P, Fenneteau O, Da Costa L, Peyrard T, Coghlan G, Illum N, Birgens H, Tamary H, lolascon A, Delaunay J, Tchernia G, Cartron JP: A dominant mutation in the gene encoding the erythroid transcription factor KLF1 causes a congenital dyserythropoietic anemia. Am J Hum Genet 2010, 87(5):721-727.

38. Flemmer AW, Monette MY, Djurisic M, Dowd B, Darman R, Gimenez I, Forbush B: Phosphorylation state of the $\mathrm{Na}^{+}-\mathrm{K}^{+}-\mathrm{Cl}^{-}$cotransporter (NKCC1) in the gills of Atlantic killifish (Fundulus heteroclitus) during acclimation to water of varying salinity. J Exp Biol 2010, 213(Pt 9):1558-1566.

39. Seale AP, Mita M, Hirano T, Grau EG: Involvement of the cAMP messenger system and extracellular $\mathrm{Ca}(2+)$ during hyposmotically-induced prolactin release in the Mozambique tilapia. Gen Comp Endocrinol 2011 170(2):401-407.

40. Seale AP, Watanabe S, Grau EG: Osmoreception: perspectives on signal transduction and environmental modulation. Gen Comp Endocrinol 2012, 176(3):354-360.

41. Trischitta F, Denaro MG, Faggio C, Mandolfino M, Schettino T: Different effects of cGMP and CAMP in the intestine of the European eel Anguilla anguilla. J Comp Physiol B 1996, 166(1):30-36.

42. Ogryzko W, Schiltz RL, Russanova V, Howard BH, Nakatani Y: The transcriptional coactivators p300 and CBP are histone acetyltransferases. Cell 1996, 87(5):953-959.

43. Breves JP, Hasegawa S, Yoshioka M, Fox BK, Davis LK, Lerner DT, Takei Y, Hirano T, Grau EG: Acute salinity challenges in Mozambique and Nile tilapia: differential responses of plasma prolactin, growth hormone and branchial expression of ion transporters. Gen Comp Endocrinol 2010, 167(1):135-142.

44. Fiol DF, Chan SY, Kültz D: Regulation of osmotic stress transcription factor 1 (Ostf1) in tilapia (Oreochromis mossambicus) gill epithelium during salinity stress. J Exp Biol 2006, 209(Pt 16):3257-3265.

45. Notch EG, Shaw JR, Coutermarsh BA, Dzioba M, Stanton BA: Morpholino gene knockdown in adult Fundulus heteroclitus: role of SGK1 in seawater acclimation. PLoS One 2011, 6(12):e29462.

46. Shaw JR, Sato JD, VanderHeide J, LaCasse T, Stanton CR, Lankowski A, Stanton SE, Chapline C, Coutermarsh B, Barnaby R, Karlson K, Stanton BA:
The role of SGK and CFTR in acute adaptation to seawater in Fundulus heteroclitus. Cell Physiol Biochem 2008, 22(1-4):69-78.

47. Tse WK, Chow SC, Wong CK: The cloning of eel osmotic stress transcription factor and the regulation of its expression in primary gill cell culture. J Exp Biol 2008, 211(Pt 12):1964-1968.

48. Tse WK, Lai KP, Takei Y: Medaka osmotic stress transcription factor $1 \mathrm{~b}$ (Ostf1b/TSC22D3-2) triggers hyperosmotic responses of different ion transporters in medaka gill and human embryonic kidney cells via the JNK signalling pathway. Int J Biochem Cell Biol 2011, 43(12):1764-1775.

49. Tse WK, Jiang YJ, Wong CK: Zebrafish transforming growth factor- $\beta$-stimulated clone 22 domain 3 (TSC22D3) plays critical roles in Bmp-dependent dorsoventral patterning via two deubiquitylating enzymes Usp15 and Otud4. Biochim Biophys Acta 2013, 1830(10):4584-4593.

50. Evans DH: Cell signaling and ion transport across the fish gill epithelium. J Exp Zool 2002, 293(3):336-347.

51. Harley RA, Glover CN: The impacts of stress on sodium metabolism and copper accumulation in a freshwater fish. Aquat Toxicol 2014, 147:41-47.

52. Brill RW: Selective advantages conferred by the high performance physiology of tunas, billfishes, and dolphin fish. Comp Biochem Physiol A Physiol 1996, 113(1):3-15

53. Notch EG, Chapline C, Flynn E, Lameyer T, Lowell A, Sato D, Shaw JR, Stanton BA: Mitogen activated protein kinase 14-1 regulates serum glucocorticoid kinase 1 during seawater acclimation in Atlantic killifish, Fundulus heteroclitus. Comp Biochem Physiol A Mol Integr Physiol 2012, 162(4):443-448.

54. Lang F, Stournaras C, Alesutan I: Regulation of transport across cell membranes by the serum- and glucocorticoid-inducible kinase SGK1. Mol Membr Biol 2014, 31(1):29-36.

55. Baltzegar DA, Reading BJ, Douros JD, Borski RJ: Role for leptin in promoting glucose mobilization during acute hyperosmotic stress in teleost fishes. J Endocrinol 2013, 220(1):61-72.

56. Lang F, Shumilina E: Regulation of ion channels by the serum- and glucocorticoid-inducible kinase SGK1. FASEB J 2013, 27(1):3-12.

57. Tai DJ, Su CC, Ma YL, Lee EH: SGK1 phosphorylation of IkappaB Kinase alpha and p300 Up-regulates NF-kappaB activity and increases N-Methyl-D-aspartate receptor NR2A and NR2B expression. J Biol Chem 2009, 284(7):4073-4089.

58. Lang F, Stournaras C: Serum and glucocorticoid inducible kinase, metabolic syndrome, inflammation, and tumor growth. Hormones (Athens) 2013, 12(2):160-171.

59. Tse WK, Chow SC, Wong CK: Eel osmotic stress transcriptional factor 1 (Ostf1) is highly expressed in gill mitochondria-rich cells, where ERK phosphorylated. Front Zool 2012, 9(1):3

60. Nakamura M, Kitaura J, Enomoto Y, Lu Y, Nishimura K, Isobe M, Ozaki K, Komeno $Y$, Nakahara F, Oki T, Kume H, Homma Y, Kitamura T: Transforming growth factor- $\beta$-stimulated clone- 22 is a negative-feedback regulator of Ras / Raf signaling: Implications for tumorigenesis. Cancer Sci 2012, 103(1):26-33.

61. Pinheiro I, Dejager L, Petta I, Vandevyver S, Puimège L, Mahieu T, Ballegeer M, Van Hauwermeiren F, Riccardi C, Vuylsteke M, Libert C: LPS resistance of SPRET/Ei mice is mediated by Gilz, encoded by the Tsc22d3 gene on the X chromosome. EMBO Mol Med 2013, 5(3):456-470.

62. Takahashi H, Sakamoto T: The role of 'mineralocorticoids' in teleost fish: relative importance of glucocorticoid signaling in the osmoregulation and 'central' actions of mineralocorticoid receptor. Gen Comp Endocrinol 2013, 181:223-228

63. Jin HO, Seo SK, Kim YS, Woo SH, Lee KH, Yi JY, Lee SJ, Choe TB, Lee JH, An S, Hong SI, Park IC: TXNIP potentiates Redd1-induced mTOR suppression through stabilization of Redd1. Oncogene 2011, 30(35):3792-3801.

64. Kim JY, Chu K, Kim HJ, Seong HA, Park KC, Sanyal S, Takeda J, Ha H, Shong M, Tsai MJ, Choi HS: Orphan nuclear receptor small heterodimer partner, a novel corepressor for a basic helix-loop-helix transcription factor BETA2/neuroD. Mol Endocrinol 2004, 18(4):776-790.

65. Kaczynski J, Zhang JS, Ellenrieder V, Conley A, Duenes T, Kester H, van Der Burg B, Urrutia R: The Sp1-like protein BTEB3 inhibits transcription via the basic transcription element box by interacting with $\mathrm{mSin} 3 \mathrm{~A}$ and HDAC-1 co-repressors and competing with Sp1. J Biol Chem 2001, 276(39):36749-36756.

66. Kim D, Pertea G, Trapnell C, Pimentel H, Kelley R, Salzberg SL: TopHat2 accurate alignment of transcriptomes in the presence of insertions, deletions and gene fusions. Genome Bio/ 2013, 14(4):R36 
67. Anders S, Pyl PT, Huber W: HTSeq - a Python framework to work with high-throughput sequencing data. Bioinformatics 2014.

doi:10.1101/002824.

68. Alexa A, Rahnenfuhrer J: topGO: Enrichment Analysis for Gene Ontology; 2010. Bioconductor package version 2.6.0. [http://www.bioconductor.org/ packages/release/bioc/html/topGO.html.]

doi:10.1186/1471-2164-15-1134

Cite this article as: Wong et al.: Discovery of osmotic sensitive transcription factors in fish intestine via a transcriptomic approach. $B M C$ Genomics 2014 15:1134.

\section{Submit your next manuscript to BioMed Central} and take full advantage of:

- Convenient online submission

- Thorough peer review

- No space constraints or color figure charges

- Immediate publication on acceptance

- Inclusion in PubMed, CAS, Scopus and Google Scholar

- Research which is freely available for redistribution 